\title{
The Venture Elusion of C2C E-Commerce in Online Marketing
}

\author{
Yanni Li a , Peiyu Li, Baichao Gong, Pengfei Shao and Changlei Cui \\ School of Foreign Languages, Changchun Institute of Technology, Jilin 130012, China \\ aliyanni2007@163.com
}

Keywords: E-commerce; risks, venture elusion; marketing.

\begin{abstract}
With the development of information technology, e-commerce, a new type of business model facilitated by Internet has been prosperous in recent years. In Europe and the US, even in China, e-commerce has been widely accepted by consumers. However, e-commerce faces many security challenges which affect not only the wide spread of e-commerce, especially C2C e-commerce. C2C e-commerce is a fast-growing business area, which usually refers to the business model that focuses on providing a platform to allow an individual to trade or barter goods and services with another individual. Due to the risks in C2C e-commerce, the wide usage of this online marketing mode is restrained. Through the discussion on e-commerce security, the paper intends to offer the venture illusion of C2C e-commerce in online marketing, which gives people some advice in this field. For buyers, they can know how to protect their own interests by choosing an honest seller, and avoiding being cheated. Meanwhile, for sellers, they can know how to judge whether a buyer is honest or not, because there are more and more dishonest buyers who begin to focus on cheating sellers, especially those new sellers by obtaining goods without payment. This paper hopes to enlighten $\mathrm{C} 2 \mathrm{C}$ business traders in this field and enhance the security system in this mode.
\end{abstract}

\section{Introduction}

The rapid development in information technology has bridged the gap and improved links between people of the world. A consequence of such wide reaching contact among people is the boost in international trade. Although the proliferation of international business is also due to liberalization of the economy and the removal of trade barriers between countries, it is indisputable that the availability of the Internet has been the catalyst. Nowadays, people are located in different geographical areas, but in fact are living in one "global village". Transactions within the "global village” are mainly carried out by means of e-commerce, conducted over computer networks.

Since e-commerce was introduced to China, it has been developed by many Chinese merchants to earn money as a means of transaction. More and more Chinese people involve in e-commerce, especially $\mathrm{C} 2 \mathrm{C}$ e-commerce. Therefore, e-commerce will be the most prevailing medium to do business in the near future. However, with the development of information technology, the security of online transaction will be paid much more attention, both from the consumers and the merchants. Therefore, how to avoid the venture of $\mathrm{C} 2 \mathrm{C}$ e-commerce in online marketing has been a hot topic in recent years.

\section{The current situation of E-commerce in China}

E-commerce has made a great development in China. The growth rate of global e-commerce in 2004 was $25.3 \%$, and the gross sales were $\$ 2774.8$ billion. Its transactions accounted for $15 \%-20 \%$ of the global trading [1].

The concept of e-commerce was introduced into China in 1993, and the first online transaction in China was done in 1996. In 1998, the e-commerce demonstration project between enterprises aiming to promote informationization of the national economy was initiated. The transfer of e-commerce from concept to practice started in 1999. The development of e-commerce showed a sound momentum in China. However, the fracture of the Internet bubble of 2000 seriously impacted the development of e-commerce. While with the rising of value-added service and the maturation of 
operating environment, e-commerce developed rapidly since 2002. The growth rate of China's e-commerce in 2004 was $73.7 \%$, and the turnover reached 480 billion RMB, accounting for $2 \%$ of the global e-commerce turnover [1].

From the view of fundamental conditions, though the developing environment for China's e-commerce is turning better, there are still some restriction factors. Up to the end of January 2007, there were over 137 million Chinese netizens. The large number of netizens provided unlimited space for the development of e-commerce. In terms of logistics, there were over 1000 distribution centers established in China by the end of 2004, including some foreign logistics corporations and delivery powers. As far as payment is concerned, the total volume of online payment was 680 million Yuan in 2004 and the figure is predicted to reach 1.57 billion Yuan in 2005.

However, among the numerous Chinese netizens, only $18 \%$ of them have the experience of purchasing online. And only $37.9 \%$ of the $18 \%$ netizens choose to pay online (with PayPal and other kinds of online payment tools), while the rest still refers to go to post offices or banks (to deposit the money to the seller's account directly, which is not safe.), showing that the functions of online payment are not perfect yet and the netizens still have some doubt on online payment. As for logistics, high delivery cost caused by the small scale of some logistics enterprises is still an obstacle for the development of e-commerce.

E-commerce is an activity which contributes to achieving economic development, but to realize this, the elements of safety, reliability, trust, and sense of security are extremely important. Because of this, the security countermeasures for each objective are critical factors for achieving adequate service. This point is an element that has been lacking in information systems until now. Especially in regard to e-commerce, where settlement is the key activity. It goes without saying that in such a society, it is necessary to maintain safety and completeness. In the network society, it is essential for systems always to be alert to attacks and threats of attacks involving crimes such as impersonation, hacking, wiretapping, altering information, cracking security barriers, etc. Countermeasures against such threats should include not only purely technical measures such as encryption, IT, etc, but also measures based on other fields such as operations, updating and improving laws, social rules, customs of daily life, and culture.

E-commerce faces many security challenges that affect wide spread use of e-commerce. Fundamentally there are three ways to obtain electronic information for unauthorized users: copy it during transmission, access it during storage or obtain it from an authorized party. Firstly, computer systems involved in a trade, including the computer itself and data, must be free from unauthorized access. Secondly, communication security in an electronic business must be assured as information transferred between customer and merchant must be protected from cracking or modification of network attack since Internet communication is easy to be monitored or modified by intruders. Attacks on data transmission include eavesdropping, replay attacks and cryptanalysis. At last, how to improve security of electronic transaction it has the same importance as above. It mainly means reducing or eliminating fraud in electronic transaction for both customer and merchant, including payment and goods delivery segment [2].

Many people have written papers about the security problems in e-commerce. Qin Zhiguang wrote a paper named A Survey of E-Commerce Security. He points out e-commerce is a very active field of Internet research. A very important aspect of e-commerce is its security. Because of the variety of e-commerce applications, many security policies, protocols and techniques are involved in the development of the security. The related standards and protocols of e-commerce are studied in his paper. The general model of e-commerce security is set forth. In this model, two most important e-commerce protocols including secure sockets layer (SSL) and secure electronic transaction (SET) are analyzed. The open problems and new trends of e-commerce security are presented.

Xiao Deqin wrote a paper named Model Checking Electronic Commerce Security Protocols Based on CTL. He presents a model based on Computational Temporal Logic (CTL) methods for verifying security requirements of electronic commerce protocols. The model describes formally the authentication, confidentiality integrity, non-repudiation denial of service and access control of the electronic commerce protocols. He illustrates as case study a variant of the Lu-Smolka protocol 
proposed by Lu-Smolka. Moreover, he has discovered two attacks that allow a dishonest user to purchase a good debiting the amount to another user. And also. He compares the work with relative research works and finds that the formal way of this paper is more general to specify security protocols for e-commerce.

Most of them are related to the technology of firewall, the technology of APP gateway, the technology of Agency Service, encrypting technology, the technology of Key Management, Certification technology and so on. Therefore, they are too professional for the common people to understand. Therefore, this paper aims to simplify the complicated technology for common people to understand.

\section{The Venture Elusion of C2C E-Commerce in Online Marketing}

Due to the limited regulation and law on the internet, e-commerce in online marketing is difficult to control. Therefore, the security problem is a hot topic among the online consumers and sellers. In this part, the paper will reveal the risks through cases analysis and give the suggested approaches to reduce or avoid the venture of $\mathrm{C} 2 \mathrm{C}$ E-commerce in online marketing.

\subsection{The risks in C2C e-commerce}

There are many scams and risks in C2C e-commerce and with the development of C2C, the scams also develop. Totally it can be summarized the following 5 types. All these risks happen when buyers and sellers are trading [3]. All the buyers and sellers should pay more attention to these risks and scams. Firstly, don't use payment tools when trading. Secondly, exchange the package by Express Company. Thirdly, don't finish payment but pretend to have completed it. Fourthly, pretend to be the buyers who have paid to cheat the goods. "Triangle scam” (Especially refer to those virtual goods.) Last but not least, claim that the there is something wrong with the goods or even haven't received the goods. "Illusive claim", especially refer to those virtual goods.

\subsection{The venture illusion of $\mathrm{C} 2 \mathrm{C}$ e-commerce}

The 5 types of risks in C2C e-commerce have been mentioned in the previous part, but solutions to them is a big potato for the buyer and seller. Take the first and second points as the example, there are some cases which can help us to see the reality.

Case One: Buy-It-Now, but off eBay

EBay seller has a "click here to buy it now" link in the auction, but it is not the official eBay Buy-It-Now button. Buyer clicks on link, and is invited to buy / pay for the widget. Transaction takes place off-eBay, and buyer is unprotected in case of no delivery.

Case Two: Uninsured "Insured Payments"

EBay buyer gets an email from a seller that states the seller paid extra money for "eBay Insured Payments". Supposedly, since the seller is a member of "The eBay Purchase Protection Program", the buyer will be refunded up to $100 \%$ or $\$ 10,000$ if anything goes wrong with the transaction. The eBayer agrees, sends the money to the seller, and waits and waits and eventually sends an email to "eBay Purchase Protection Program”. The email bounces. There is no such program. The seller scammed the buyer into believing there was an escrow program other than the one eBay approves.

Case Three: Email Me to Get Scammed

EBay buyer finds a particularly good deal, but the auction states potential bidders must email the seller to get the "Buy-It-Now" price, and get approved to bid. Since the buyer really wants a good deal on the widget, he/she emails the seller. Seller replies. The scam can go in either or both of these directions at this point: Seller asks for immediate payment -- but states his/her PayPal account is temporarily having problems, so buyer must send a money order or Western Union payment instead. Buyer sends money, while Item never arrives. Since it was a non-eBay deal, there is little recourse for the buyer. Seller's return email has a "click here to bid on my auction". Buyer clicks, and logs into "eBay”. However, it was not really eBay. Buyer just left private ID info at a scam site, and later learns his/her ID was hijacked.

Then how to solve the problems? The venture is that don't use PayPal or other payment tools when trading. It widely happens in $\mathrm{C} 2 \mathrm{C} \mathrm{e}$-commerce. It is the biggest problem in $\mathrm{C} 2 \mathrm{C}$ e-commerce. $\mathrm{C} 2 \mathrm{C}$ is 
quite different from traditional trade. In traditional form of trading, we just pay the cash to the seller face to face and then get the goods. However, in C2C e-commerce all the payments should be completed online. How does the money be paid to the seller? Of course it can be posted to the sellers' account, but it is not safe. Because after the seller has received the money, if he is a dishonest one, he can refuse to make delivery easily. So at this time we should use the third-party payment tools.

\section{Summary}

E-commerce can be a friend or a foe for consumers and merchants. Consumers can benefit from web shopping by having better choice, with greater ease, and a potentially lower cost for goods and services. Merchants can find more consumers through e-commerce. However, due to the borderless nature of the Internet, consumers and merchants are exposed to a wider range and to new forms of infringement of their rights and interests [4]. Online consumers and merchants can no longer rely only on the traditional forms of legal protection at the national level, and there is growing concern over the safeguarding of their interests in the global shopping mall. Consequently, various models are suggested as a control mechanism for $\mathrm{C} 2 \mathrm{C}$ transactions via the Internet and are argued to be the future paradigms of consumer protection in the era of e-commerce.

In promoting e-commerce, the Chinese government has devoted considerable efforts to constructing the sophisticated technical infrastructure necessary to support and develop online commercial activities. The government has also announced a range of Internet regulations as part of the legal environment for e-commerce. As far as the issue of Chinese consumer and merchant protection is concerned, the continuing role of government in online activities is desirable and necessary. It is due to the special economic circumstances and the diversity of consumer and merchant segments in China that the viability of "non-government interference" models is refuted.

E-commerce faces many security challenges that affect wide spread use of e-commerce. The study of the venture illusion of $\mathrm{C} 2 \mathrm{C}$ e-commerce in online marketing gives people some advices, shows the buyers that how to choose a honest seller to buy goods, how to avoid to be cheated, how to protect own interests. Meanwhile, more and more dishonest buyers begin to focus on cheating the seller who wants to obtain the goods without money. For the seller, the thesis also shows them how to judge a buyer is honest or not, does the best to protect sellers' interest.

\section{References}

[1]. Xiaozhen Xu. E-commerce. Higher Education Press, 2006, p212-213.

[2]. J. Paul Peter, Jerry C.Olson.Marketing behavior and marketing strategy.McGraw-Hill, 2001, p90-92.

[3]. Edward J.Deak. E-Commerce and Network Economics.Northeastern Finance University, 2006, p 50-52.

[4]. Gary P.Schneider.E-Commerce (English Version). Mechanics Industry Press, 2006, p 27-29. 